\title{
Serge Genot*
}

\section{Libraries of French Higher Education}

\author{
A Take-off in the Clouds of SaaS
}

DOI 10.1515/bfp-2016-0070

\begin{abstract}
Over the last 2 years, French Bibliographic Agency for Higher Education (ABES) and 46 academic institutions have been dissecting the main next generation library systems. This group represents almost $60 \%$ of university libraries in France. Its work has prompted the providers to enhance their solutions and to lower the rates of SaaS. Market rules will guarantee a long-lasting competition between the main solutions. The first deployments will start in January 2017.
\end{abstract}

Keywords: Library; Experience; SaaS; France; 2017

\section{Französische Hochschulbibliotheken. Das Abheben in die Sphären von SaaS}

Zusammenfassung: Die französische „agence bibliographique de l'enseignement supérieur" (ABES) und weitere 46 akademische Institutionen haben in den letzten zwei Jahren ihre bisherigen Bibliotheksinformationssysteme analysiert. Diese Institutionen vereinigen fast $60 \%$ aller Hochschulbibliotheken Frankreichs, was die Anbieter von Software-as-a-Service (SaaS) dazu veranlasste, ihre Angebote $\mathrm{zu}$ verbessern und die Preise $\mathrm{zu}$ senken. Durch die Wettbewerbs- und Marktregeln wird somit ein langandauernder Wettbewerb zwischen den Anbietern garantiert. Der Ersteinsatz der neuen Software wird ab Januar 2017 anlaufen.

Schlüsselwörter: Bibliothek; Erfahrungen; SaaS; Frankreich; 2017

\section{Welcome aboard}

The wings of an immediate take-off with a competitive dialogue were multi-awarded.

The gestation of this project took its time. The first opportunity to study the subject by a group of scientists goes back to 2010. The idea of the project sprang up from

\footnotetext{
*Corresponding author: Serge Genot, genot@abes.fr
}

left at first several observations: The expensive multiplicity of the Management IT system of library in the French establishments with 18 different software; ageing solutions installed since 10-20 years for some; proprietary solutions with a weak interoperability between the various software components of documentary information systems (Management IT system of library, Electronic Resource Management and link resolver); also isolated from with external management applications and the national cataloguing system; last but not least these solutions don't handle properly electronic resources, which is obviously a key issue.

Even if the concern of local systems is not in the scope of its initial missions of the ABES, ${ }^{1}$ given the potential economies of scale, ABES was asked to co-lead a national study on the implementation of a mutualised Management IT system of library (SGBm project). Another issue was to secure the consistency between the national systems administered by ABES for libraries and SGBm. This study led to the creation of a grouping of command (GC) made of 46 institutions and to the launch of a multi-awarded contract with a competitive dialogue.

This grouping represents about $60 \%$ of establishments of French higher education. This considerable weight allowed setting up a work force multiplied to drive direct the market participants in the desired sense. Nine experimental sites and ABES lead competitive dialogue with the main suppliers of the market. Nearly 145 people work in a highly structured organisation that takes full advantage of the fluidity and the proactivity brought by collaborative tools 2.0. Thirty experts are regularly requested within eight functional commissions and seven workshops in charge of project engineering. Decisionmakers also provide expertise in working groups whose concerns are primarily organisational and financial aspects.

This strength operates under the control of a steering committee composed of major actors of the higher education and of the French research. This force is put in the

1 Bibliographic Agency for Higher Education (ABES). 
service of competitive dialogue multi-awarded. This installs a "win-win" dialogue and sustained competition between suppliers for nearly 20 months. The suppliers benefit from very precise specifications concerning 250 features and 70 practical cases at the heart of the job. The finalisation of this document has mobilised more than thirty experts. The dialog allows to adapt the new generation SGB to specifications and to develop pricing models to the French context. This dialogue is very seriously taken by 5 suppliers hold in hearing; they invested on average more than 250 days men to answer it. In the end, this dialogue has mobilised more than 1,150 days of experts quoted experimental sites and ABES. The proposed solutions were shelled in detail by national and local teams.

Take-off into the clouds of SaaS is now imminent. A tender commission will select only part of the five candidates auditioned to integrate the framework agreement. In some kind of way, they will be certified "fit for service" with a maximum price. The stake is high for suppliers. French institutions renew their documentation system only every 10 or 15 years; not being certified is synonymous with great difficulties on the French market for a long time. The certified solutions will then be handed in competition through the different waves of the 46 institutions. Prices can only fall. The first wave of departures will be one of the experimental sites. Initial deployments will begin in January 2017. Other waves will break out then over the next four years. It is interesting to note that an open source solution is among the candidates interviewed. Everyone is aware of the lever that constitutes this type of solution to control rising market costs over the long term.

\section{Turbulence zones}

The competitive dialogue allowed to identify the potential zones of turbulence and to get ready for it. They are economic, technical, and organisational.

The economic issue is a key concern. This was both to influence the tariff negotiations and ensure sustainable competition between suppliers to avoid a captive market. The weight of $60 \%$ of French institutions in the negotiation table helped shake up pricing system towards greater transparency and lower prices. The principle of multi-attribute market guarantees a long-lasting competition in the medium term. With each wave of deployment, there is a reopening of competition among certified solutions. The availability of an open source solution among the certified solutions is an additional lever to lower rates. Negotiations are still ongoing.
A study ${ }^{2}$ commissioned by the $\mathrm{ADBU}^{3}$ allowed comparing the case of libraries having opted for new generation type "cloud" systems with user libraries of classic systems. This study focused on identifying the "total cost of ownership" of the system: the cost directly related to the system (licenses, maintenance of the database and servers etc.), the costs related to the operational management of the system (administration, training, support etc.), the efficiency of workflows coming along with the system (which corresponds to the human resources portion engaged in any aspect thereof), long-term costs related to developments system.

One lesson from this study is the lack of proven business model for next-generation systems. The adoption of a cloud library management system type is translated into gains only if the institution reorganised its working circuits to exploit the opportunities offered by these systems, either in integration with external applications (platforms for content providers, but also and especially the financial system of the university) or sharing of data across a regional network, national or global community system users.

Technical and organisational constraints are critical in the success of the new systems. It was necessary above all for the software offers to adapt to the specifics of French universities or raise rates. This objective was fully achieved. More than twenty months of competitive dialogue helped to move the lines in the desired direction. This included establishing an ever more integrated approach between the syndicated size of establishments, the local information system, and the national system (Sudoc). It was also a better articulation between paper and electronic collections, with a flow of processing these materials (in terms, acquisition, processing, use etc.). Finally, it was necessary to connect to a more important number of international databases as well as ensuring open solutions (API, web services, service oriented architecture etc.). All of these are under control.

Finally, institutions reorganise to standardise their practices against the acceleration of regional groupings of institutions (COMUE). The transition to a shared SGB solution is facilitated if the organisation of a service or establishment is naturally compatible with this change. Institutions also are considering pooling their resources in production phase (on the training for example). Institutions will have a national backup of their data to ensure control of their data, particularly in cases of divorce supplier.

$2 \mathrm{http}$ //demeter.univ-toulouse.fr/reinformatisation/retour-sur-letu de-de-ladbu-sur-les-consequences-economiques-et-organisationnel les-du-choix-dun-sgbm.

3 Association of the directors and the staffs of direction of university libraries and the documentation. 
The competitive dialogue has generated other benefits. It has accelerated the transition of publishers to next generation approaches. It has enhanced the industrialisation process deployments. It allowed capitalising on a knowhow, a knowhow concerning making other people do and knowledge about informing. It also developed the art of getting quick consensus ... despite the large number of players!

\section{Take some height}

The SGBm project enabled both to rethink the complexity of the relationships between local, regional and national levels and reinvent close cooperation between these levels.

All the solutions studied were not ready to flexibly manage the variety of French organisations and cooperation or interoperations of territorial levels with national union catalogues. It was necessary to force the suppliers to structure better their offer in three levels:

- international level: global data and services to all libraries sharing system

- $\quad$ syndicated level: data and services specific to a group of libraries

- local level: own data and services for a particular library

At the end of the day, there will remain no inconsistency between the local level and other levels.

Good local integration of this complexity requires change management support. Experience shows that it takes at least a year to prepare the data for migration to SGBm solutions and as much to reorganise services. Many fact sheets will be made available to members of the grouping commands. It should also organise training of trainers according to a national approach, linked with other national actors in training. The scenarios are built with the institutions.

The project allowed moving towards a closer association in decision-making institutions concerned by the services offered by ABES and future sharing axes, whether national or merely associated with each wave of deployment. We are entering into a virtuous process of continuous improvement of services, listening to the institutions and in line with the strategic priorities of ABES; a logic that also draws on best practices of ITIL V3 framework.

The evolution of the services offered by ABES is interesting to point out. According to the project phases, the services offered are different. During the competitive dialogue, we were in the project ownership assistance but also in assisting with project management experimental sites.
ABES will not have this level of assistance for members of the grouping of command during the deployment phase. Other pooling axes will emerge: IT co-development; training and media with sharing platforms (presentation, scripts); coordinate data collection needs; production, enrichment and correction data; strategic organisation of local initiatives etc.

\section{Reach for the stars}

Project issues are not just on the national level, they interfere with a mapping of international actors.

Publisher's solutions have international power such that they could move into a quasi-monopoly, with all the related risks.

It is crucial to agree internationally to remain master of our cataloguing standards, our metadata and move towards a shared repository authorities that transcends boundaries, including our Francophonie (idref, Rameau, future national authorities file $\mathrm{ABES} / \mathrm{BNF}$ ). The issue of the architecture of such systems becomes crucial. How to work/lean on/multiple authority files (physical persons, legal persons, materials, works etc.) and have as much as possible formats allowing multilingual search?

One can also wonder about the opportunity to carry at the international level the emergence of free software and open source solutions. They are an effective bulwark in tariff drifts of proprietary solutions on the market. Recent major solutions acquisitions are not reassuring regarding sustainable competition conditions.

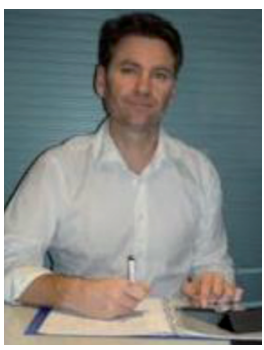

Serge Genot

ABES

227 avenue Professeur Jean-Louis Viala CS 84308

F-34193 MONTPELLIER CEDEX 5

Frankreich

genot@abes.fr 